\title{
Impact of Obesity on Nuclear Medicine Imaging
}

\author{
Mohammad A. Ghanem, Nafeesa A. Kazim, and Abdelhamid H. Elgazzar \\ Department of Nuclear Medicine, Mubarak Al Kabeer Hospital, Jabriya, Kuwait; and Department of Nuclear Medicine, Faculty \\ of Medicine, Kuwait University, Safat, Kuwait
}

\begin{abstract}
Obesity, with its alarming increase among adults and children, represents a significant health problem with serious medical, social, psychologic, and economic reverberations. The burden of this problem significantly affects the medical care system, including medical imaging. The effect of obesity on nuclear medicine imaging spans many aspects, from preimaging patient preparation to radiotracer administration, image acquisition, and image interpretation. The acquired images may be suboptimal because of artifacts due to soft-tissue attenuation and incomplete whole-body coverage, and quantification may be suboptimal, especially for PET. Other difficulties include mechanical problems such as the weight limit of the imaging table and the bore size of the PET or SPECT/CT scanner and the need to alter the timing, duration, or protocol of many imaging procedures. These issues are discussed in this review, which clarifies the impact of this epidemic health problem on nuclear medicine services and proposes possible solutions to overcome obesityrelated difficulties encountered in nuclear medicine practice.
\end{abstract}

Key Words: obesity imaging; nuclear medicine; imaging

J Nucl Med Technol 2011; 39:40-50

DOI: $10.2967 /$ jnmt.110.078881

O

besity, a complex condition representing a significant health problem with serious medical, social, and psychologic reverberations, affects virtually all ages and socioeconomic groups. It has reached an epidemic figure globally, with more than 1 billion overweight adults, at least 300 million of whom are clinically obese (1-9). Forming a large economic burden, obesity has been estimated to account for $2 \%-7 \%$ of the total health care cost in several developed countries (10).

Additionally, obese and overweight children are a growing concern. This disorder has doubled in children 10-17 y old over the last decade, making it the most prevalent childhood nutritional disorder in many parts of the world (11).

Obese individuals encounter more health problems throughout the course of their lives. Because of the alarming rate at

\footnotetext{
Received May 11, 2011; revision accepted Oct. 29, 2010.

For correspondence or reprints contact: Abdelhamid Elgazzar, Department of Nuclear Medicine, Kuwait University, P.O. Box 24923, Safat, Kuwait, 13110.

E-mail: aelgazzar49@hotmail.com

COPYRIGHT @ 2011 by the Society of Nuclear Medicine, Inc.
}

which the number of obese patients, both adults and children, is increasing, a bigger burden is being placed on the medical care system as it deals with obesity-related problems (12). One such problem is radiologic images that are difficult to perform and interpret (13). This review discusses these difficulties and suggests ways to overcome them.

The effects of obesity on imaging can be classified into preimaging, imaging, and postimaging categories.

\section{PREIMAGING CONSIDERATIONS}

Obesity affects several preimaging aspects, including calculation of radiopharmaceutical activity, injection of the radiopharmaceutical, and preparation of the patient.

\section{Administered Activity}

The standard activity of radiopharmaceuticals in adults is based on the ideal standard weight of a patient, $70 \mathrm{~kg}$ (14). Parameters such as pregnancy and sometimes renal function are considered limiting factors in the radiation dose delivered to the patient. Obtaining acceptable image quality in an obese patient frequently requires use of an activity higher than used in a patient of ideal weight. However, the radiation dose to the patient recommended by the International Commission on Radiological Protection limits the increase in activity, and hence the dose may not be high enough to produce an adequate study for proper interpretation due to a reduced signal-to-noise ratio and increased scatter in the acquired image. In PET, for example, an increase in the injected dose according to patient weight can be used to overcome poor image quality due to scatter, but the dose cannot exceed $925 \mathrm{MBq}(25 \mathrm{mCi})$ of ${ }^{18} \mathrm{~F}$-FDG (15). A common procedure used in myocardial perfusion imaging is to calculate the activity on the basis of patient weight and adjust upward for heavier patients by using a fixed formula dose such as $11.47 \mathrm{MBq}(0.31 \mathrm{mCi}) / \mathrm{kg}$ for ${ }^{99 \mathrm{~m}} \mathrm{Tc}$ agents or $1.48 \mathrm{MBq}(0.04 \mathrm{mCi}) / \mathrm{kg}$ for ${ }^{201} \mathrm{Tl}$. Another option to overcome this limitation and improve image quality is to lengthen the acquisition time or use a multidetector system for higher statistical counts $(14,16)$.

\section{Injection}

Subcutaneous adipose tissue in obese patients can act as a barrier to visualization and palpation of the underlying vascular structure and make intravenous access cumbersome. Such cases should be dealt with by more experienced nuclear 

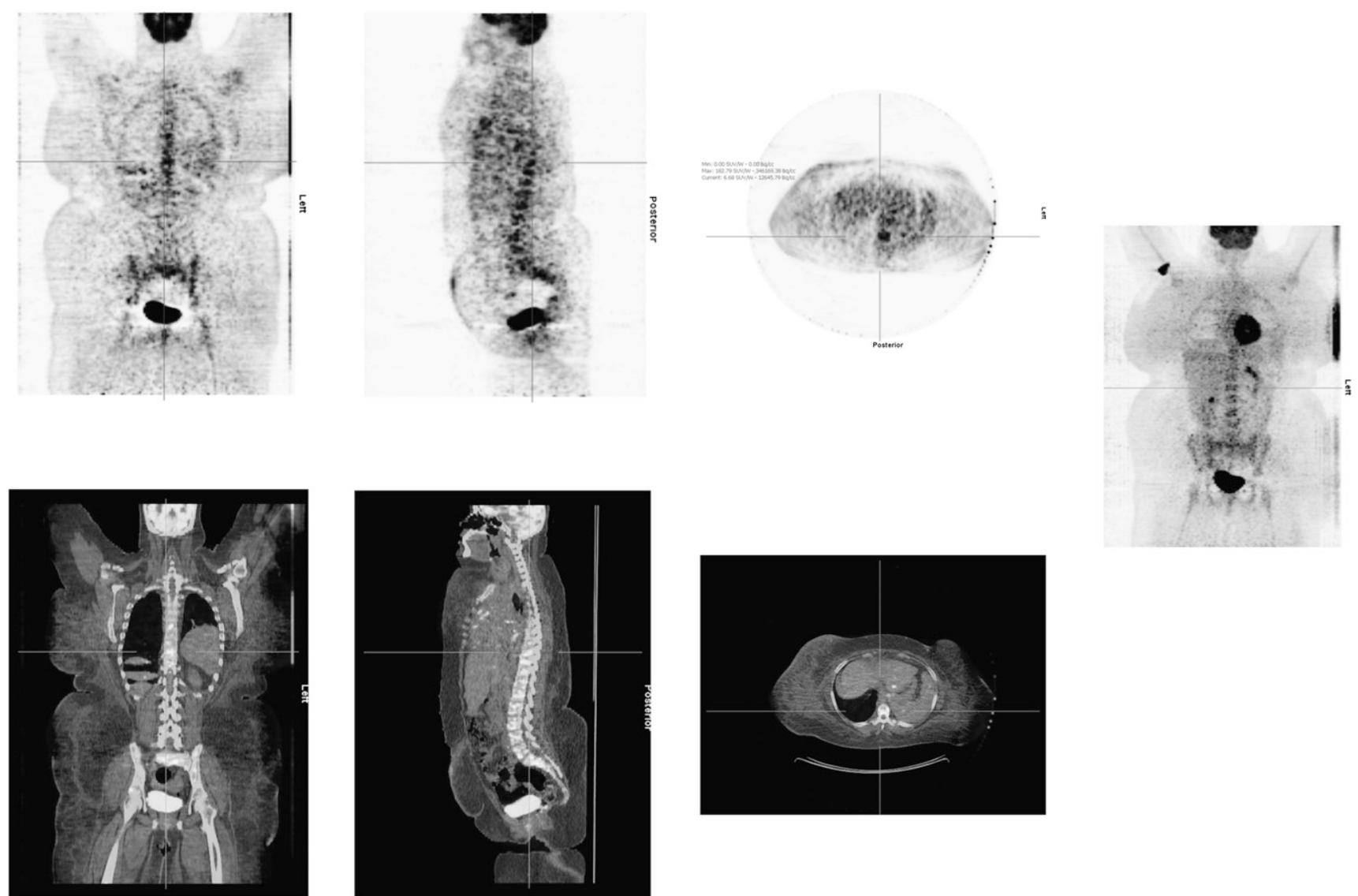

FIGURE 1. Whole-body PET/CT scan of 48-y-old woman (body mass index, 39; blood glucose level, $101 \mathrm{mg} / \mathrm{dL}$, or $5.6 \mathrm{mmol} / \mathrm{L}$ ) with history of breast cancer whose body contour exceeds PET and CT field of view, causing cropping and reconstruction artifact at leftbreast region.

medicine technologists, an intravenous team, or even an anesthesiologist.

Some hospitals have sophisticated settings in which ultrasonography-guided peripheral intravenous access can be used $(17,18)$. Costantino el al $(19)$, in studying a subgroup of 60 patients with difficult intravenous access, concluded that ultrasonography-guided peripheral intravenous access is more successful than traditional blind techniques, requires less time, decreases the number of percutaneous punctures, and improves patient satisfaction.

\section{Patient Preparation}

In addition to the well-known aspects of patient preparation before a nuclear medicine study, such as good hydration, fasting, body hair shaving for cardiac studies, and specific drug cessation, some special considerations should be kept in mind in obese or overweight patients, such as the amount of hydration (when required in some studies) and longer acquisition times. Greater fluid intake should be encouraged because, among other factors, adequate hydration is dependent on the patient's weight. The patient should be told how long an acquisition is expected, since this will encourage greater cooperation by the patient during positioning and acquisition.

\section{IMAGING CONSIDERATIONS}

\section{Patient and Staff Safety}

Obese patients generally need more staff assistance. Patient transfer from stretcher or wheelchair to the imaging table may be cumbersome, and the patient may fall and be injured if not carefully assisted. Any accessory gadgets such as mobile steps and walkers available in the imaging room should be used to prevent possible injury to the patient. Furthermore, the members of the staff may be given special training on how to use an assistive device, such as a Hoyer lift, to reduce their chance of being injured while attempting to lift or transfer obese patients. If patient transfer is still a problem, it is recommended that a mobile $\gamma$-camera, if available, be wheeled to the patient's stretcher.

\section{Camera Setup and Limitations}

Most $\gamma$-camera tables have a weight limit of $180 \mathrm{~kg}$ (400 lb). It is unsafe for overweight patients to be positioned on a $\gamma$-camera table if the maximum bearing weight is exceeded. A mobile $\gamma$-camera, if available, can be wheeled to the patient's bed or stretcher for certain studies such as lung ventilation-perfusion scans. Imaging equipment that is used for heavy patients may show increased wear and tear; potential stress to the table motors requires particular attention. 
When multihead $\gamma$-cameras are used, the position of the detectors is usually adjusted automatically; however, in the case of an obese patient, the detector position may be adjusted manually to accommodate the contour of the patient. A $\gamma$-camera integrated with a CT scanner has an entrance gantry that does not exceed $80 \mathrm{~cm}$, creating difficulty in accommodating some obese patients. Artifacts such as cropping and beam hardening can occur when the patient's girth exceeds the field of view, leading to a lower sensitivity for detection of peripheral lesions (Fig. 1) (20). Even large-field-of-view cameras may not accommodate the body of the patient in whole-body imaging. Parts of the body may not be included, and additional images should be obtained. If the patient's body is larger than the bore diameter of the imaging system, the patient cannot undergo the scan, even though body weight may not exceed the limit specified by the manufacturer. New-generation scanners have promising potential advantages for the imaging of heavy patients, such as an increased table weight limit and an increased gantry bore diameter (21).

\section{Positioning}

Nuclear medicine studies generally take longer than radiologic studies. This increases the chance of patient movement during acquisition, since remaining still for long periods is uncomfortable for obese patients. Accordingly, more attention to proper and secured positioning of the patient is required to ensure acceptable image quality. Furthermore, as most acquisition protocols require the patient to be supine, the aid of pillows, splints, or even sandbags may be needed to ensure patient comfort during imaging and minimize motion under the $\gamma$-camera. Patients should be told to ask that the imaging be stopped if discomfort becomes intolerable. In such a case, the study is rendered incomplete, with only part of the imaging protocol performed (Fig. 2).

In addition, many obese patients may have a limited range of movement in the upper or lower limbs. This limitation may markedly affect the imaged area, causing attenuation artifacts in studies that require the patient's arms to be lifted above the head (Fig. 3).

Exposing the imaged area properly, as in thyroid imaging of patients who are obese and have an apparently shorter neck due to the surrounding fat tissue, is a challenge for technologists and for physicians both before and during the acquisition.

Furthermore, proper positioning of an obese patient, especially if CT is used along with PET or SPECT to include the exact volume of the patient that is being imaged, can reduce the radiation dose to that patient (22).
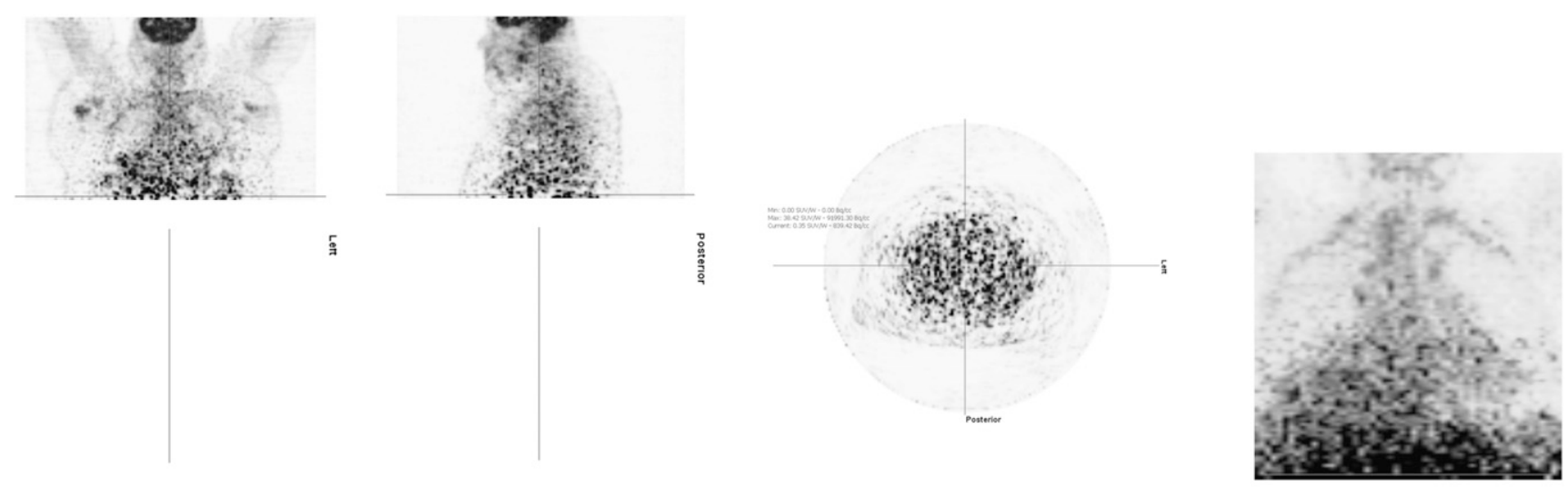

5

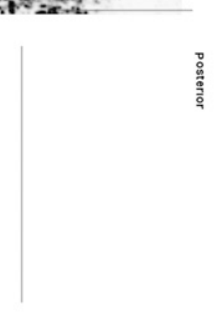

s
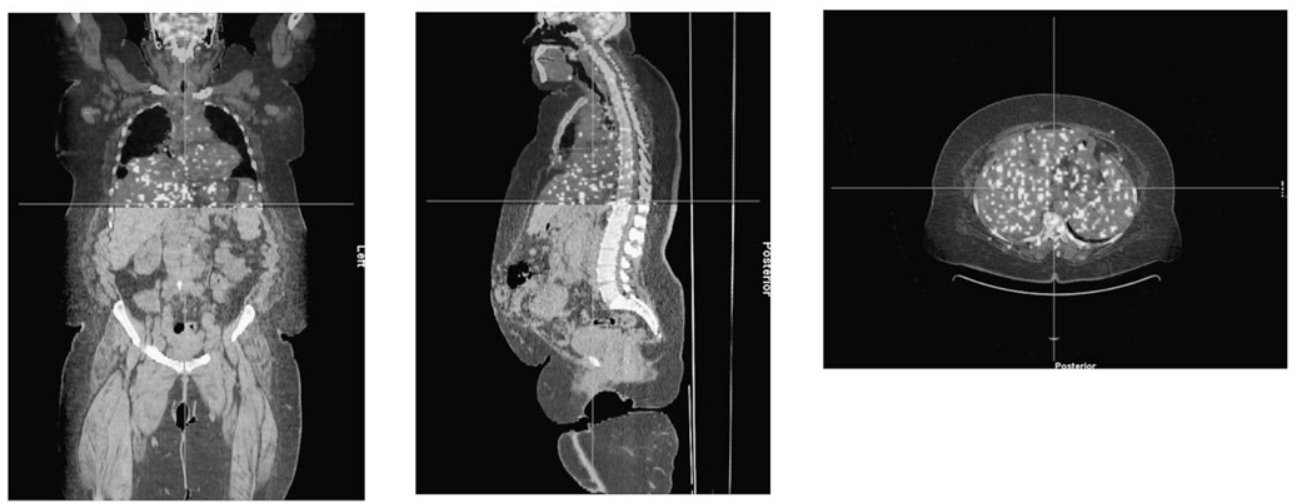

FIGURE 2. Whole-body PET/CT scan of 49-y-old woman (body mass index, 42; blood glucose level, $104 \mathrm{mg} / \mathrm{dL}$, or $5.6 \mathrm{mmol} / \mathrm{L}$ ) with history of breast cancer who was not able to complete emission part of study because of discomfort during acquisition. 


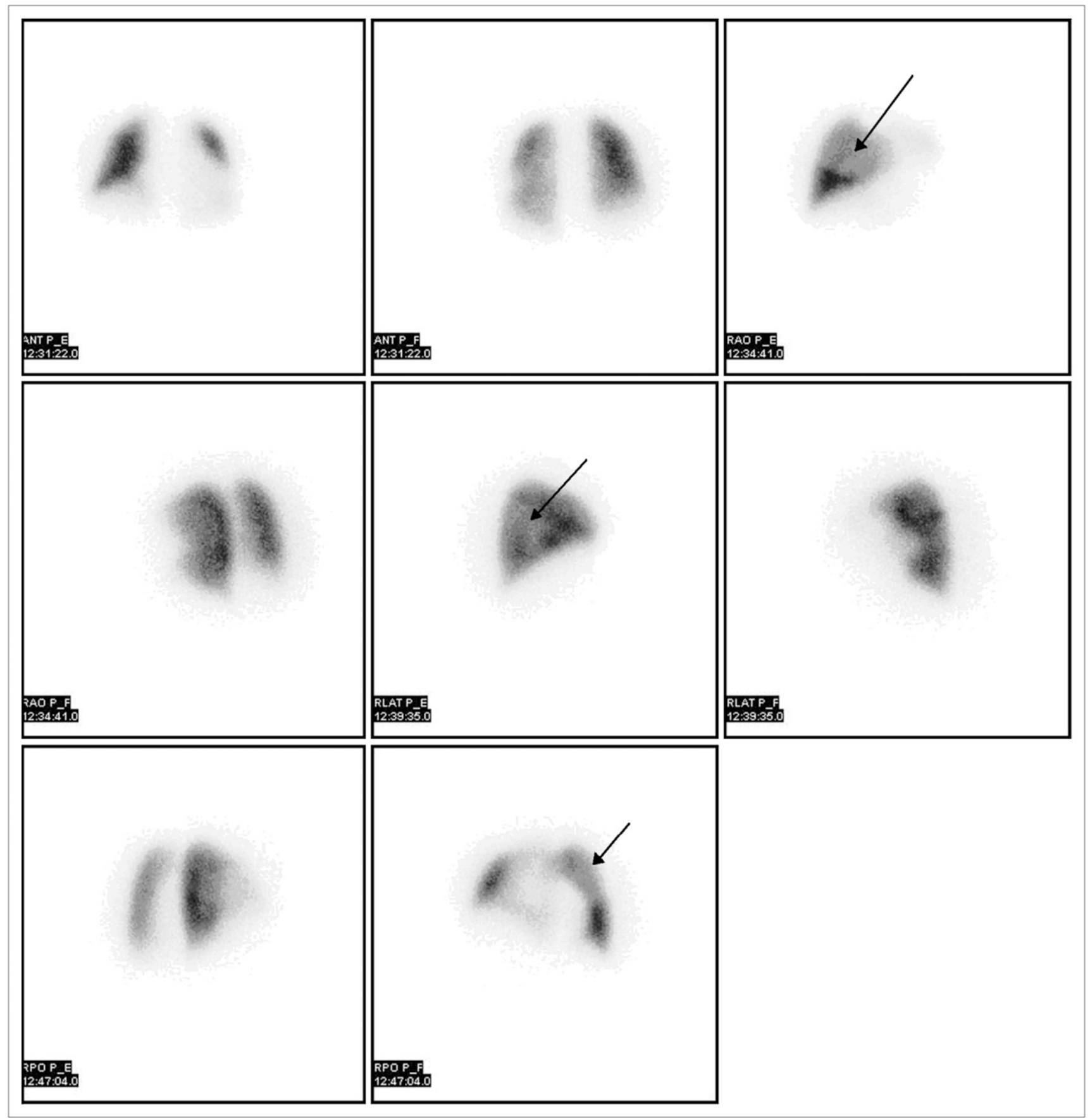

FIGURE 3. Lung perfusion images of overweight female patient who was unable to lift arms over head during acquisition, causing attenuation defects (arrows) on lateral, right anterior oblique, and left anterior oblique images.

Difficulty in positioning after all efforts may lead to suboptimal imaging, longer procedures, and increased radiation dose to the patient and technologist.

Including the entire body within the acquired images can be troublesome in obese patients. This issue is a problem in whole-body bone scans or PET scans, as parts of the body periphery may not be included in the imaged area (Fig. 4).

The standard acquisition protocol may need to be modified in obese patients. For instance, a combined supine and prone acquisition may be required to maintain the specificity of gated myocardial perfusion imaging in the diagnosis of coronary artery disease (23).

\section{Acquisition}

The number of photons reaching the $\gamma$-detector depends greatly on the amount of attenuating tissue and the geometry of the patient's body. Compton scattering attenuates primary photons reaching the $\gamma$-camera and contributes a 


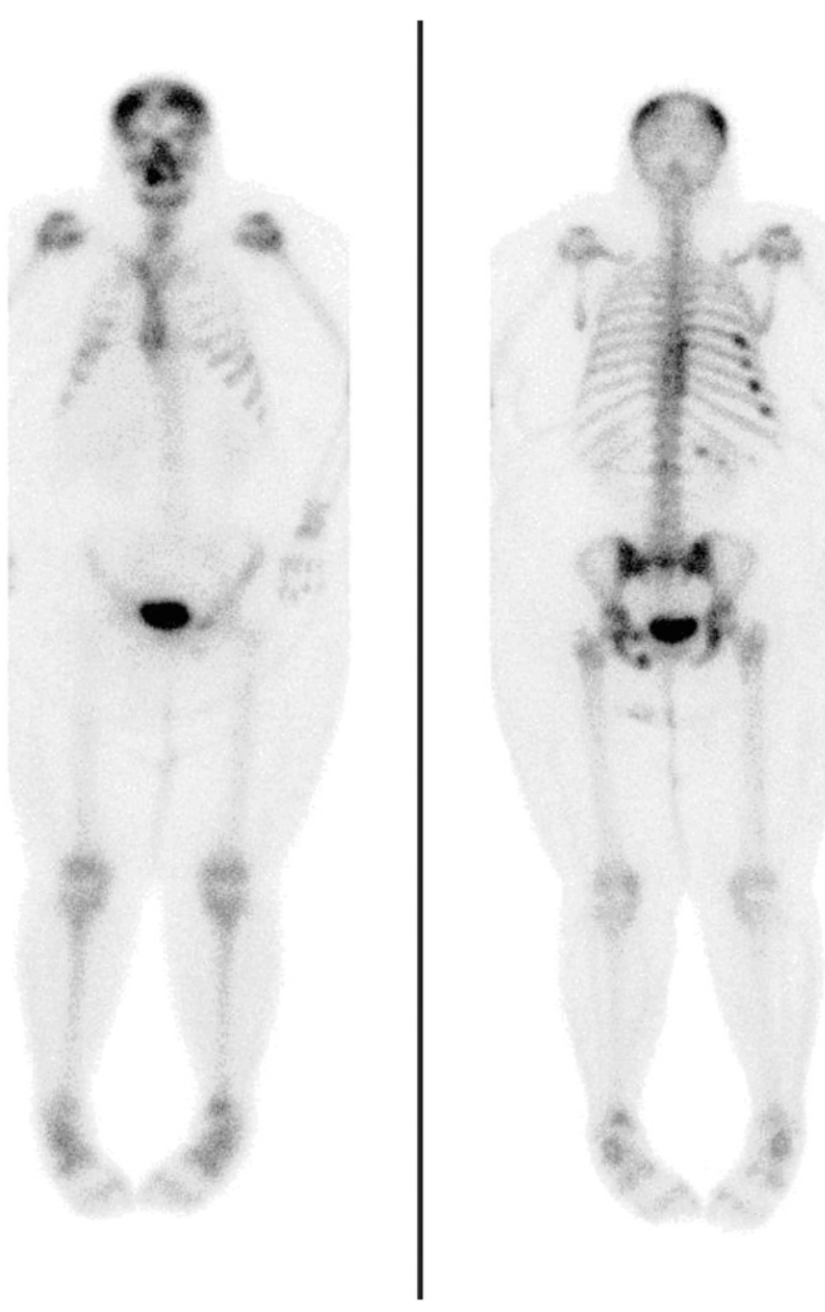

FIGURE 4. Whole-body bone scintigraphy image shows that peripheral parts of body are outside field of view of $\gamma$-camera because of patient's obesity. Most parts of upper limbs are not included in field of view.

significant amount of undesired scattered radiation to the image. The deeper the source of radiation in the patients, the greater is the buildup of scattered radiation (24). In obese patients, a frequent problem is obtaining insufficient count statistics because of soft-tissue attenuation, leading to a poor signal-to-noise ratio. To overcome this problem, acquisition time should be increased to maintain a sufficient count number $(14,20)$. It has been suggested that patients weighing $120 \mathrm{~kg}$ need a PET acquisition 2.3 times longer than that for a $60 \mathrm{~kg}$-person to obtain the same signal-tonoise ratio (25). Halpern et al., in a well-designed study (26), acquired lutetium oxyorthosilicate PET emission scans for 7 min per bed position in 25 consecutive obese patients. Single-minute frames were extracted from these scans for each patient. The investigators found that lesion detectability and reader concordance peaked on the scans acquired for $5 \mathrm{~min}$ per bed position, with no further diagnostic gain achieved by lengthening the duration of PET emission scanning. Thus, 5 min per bed position is suffi- cient for optimal lesion detection with lutetium oxyorthosilicate PET/CT in obese patients.

Delaying the acquisition in certain procedures, such as bone scanning, is also an important option to improve outcome. In such a case, static images can be delayed up to 4-5 $\mathrm{h}$ after injection to help further clear soft-tissue activity and improve target-to-nontarget ratio.

Furthermore, in obese patients, the ratio of scattered photons within the body increases, leading to a wide base photon energy spectrum due to the lower-energy scattered photons. Narrowing the energy acceptance window or using an asymmetric window can reduce the amount of scattered photons accepted during acquisition and can improve energy resolution, thus producing better images in such cases (27).

\section{Technologists' Radiation Exposure}

Potentially larger amounts of radiation exposure to technologists are expected the longer they spend with the patient for extra support during positioning and acquisition. Accordingly, changing the technologist dealing with obese patients might be considered when prolonged contact will be required and larger doses administered, particularly in PET studies (28).

\section{POSTIMAGING CONSIDERATIONS}

\section{Breast Attenuation}

Overweight patients, particularly women with large breasts, are prone to having attenuation artifacts on many studies. In myocardial perfusion imaging, artifacts within the anteroseptal wall due to breast attenuation are common (Fig. 5). In extremely obese patients, lateral wall attenuation artifacts can be due not only to scatter of photons emitted from the myocardium but also to increased distance between the heart and the surface of the $\gamma$-camera. Adding prone imaging (i.e., imaging in the supine and then prone positions) can help correct for these artifacts and, for coronary artery disease, provide diagnostic accuracy similar to that for a normal-weight patient (Fig. 6) (28). In addition, breast taping or lifting during acquisition can resolve some of this attenuation (Fig. 7). Other methods such as transmission source- or CT scan-based attenuation correction are used in many centers worldwide to increase diagnostic accuracy and reduce false-positives caused by attenuation in the overlying soft tissue (29). However, it remains to be seen whether attenuation correction may itself introduce artifacts. Breast attenuation can also be seen in other studies, such as in sulfur colloid scans, especially if the scan reaches the upper abdominal quadrants (Fig. 8).

\section{Fat Crease Attenuation and Effect on Images}

In bone scintigraphy, image quality is often limited by soft-tissue attenuation and photon scatter caused by overlying fatty tissue. A large amount of fat tissue can entirely obscure the underlying imaged organ (Fig. 9) (30). This particularly affects lesion detection on planar images, but 

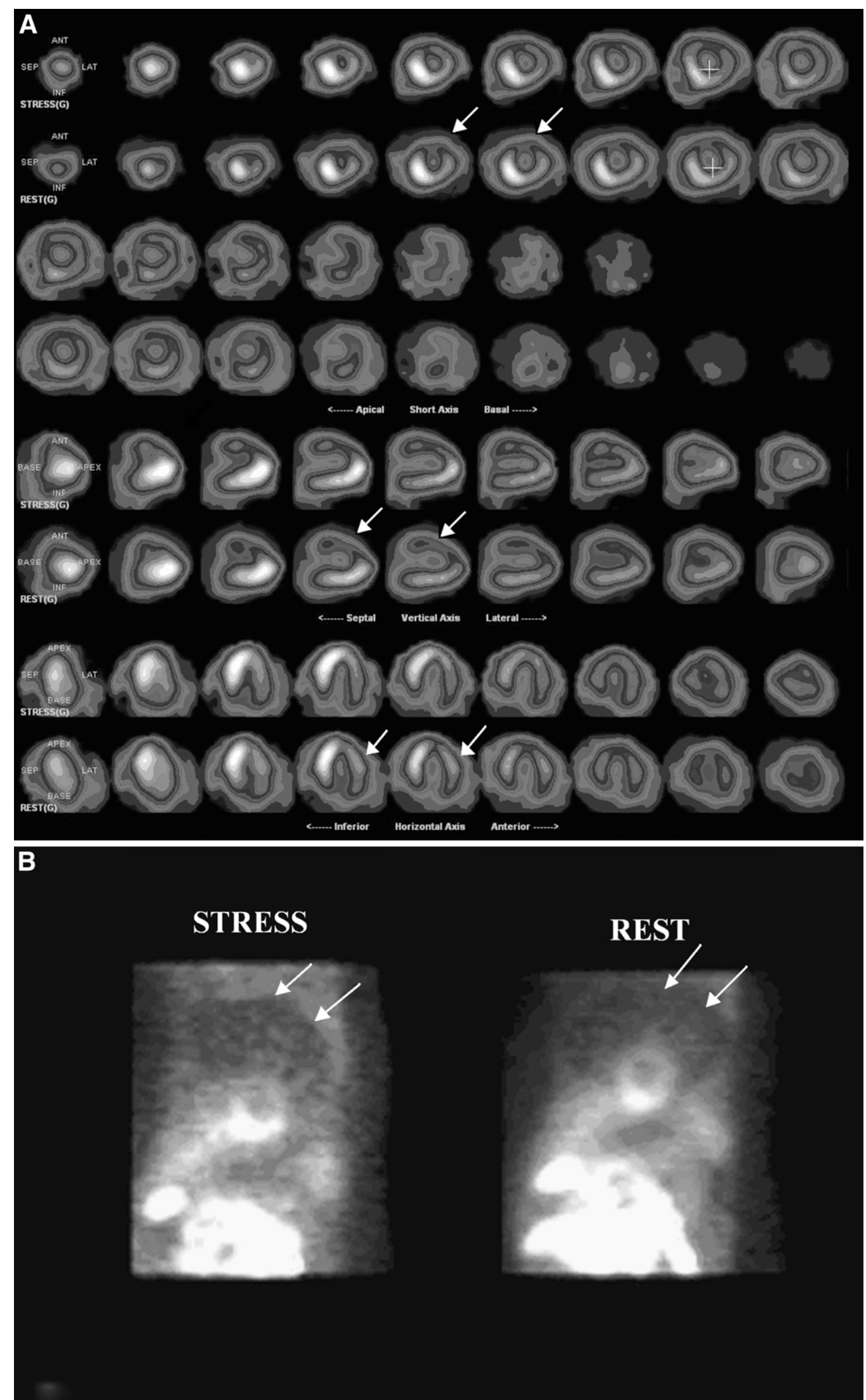

FIGURE 5. Multislice views (A) and raw images (B) show large-breast-attenuation artifact (arrows) involving anterolateral myocardial wall of obese female patient. 


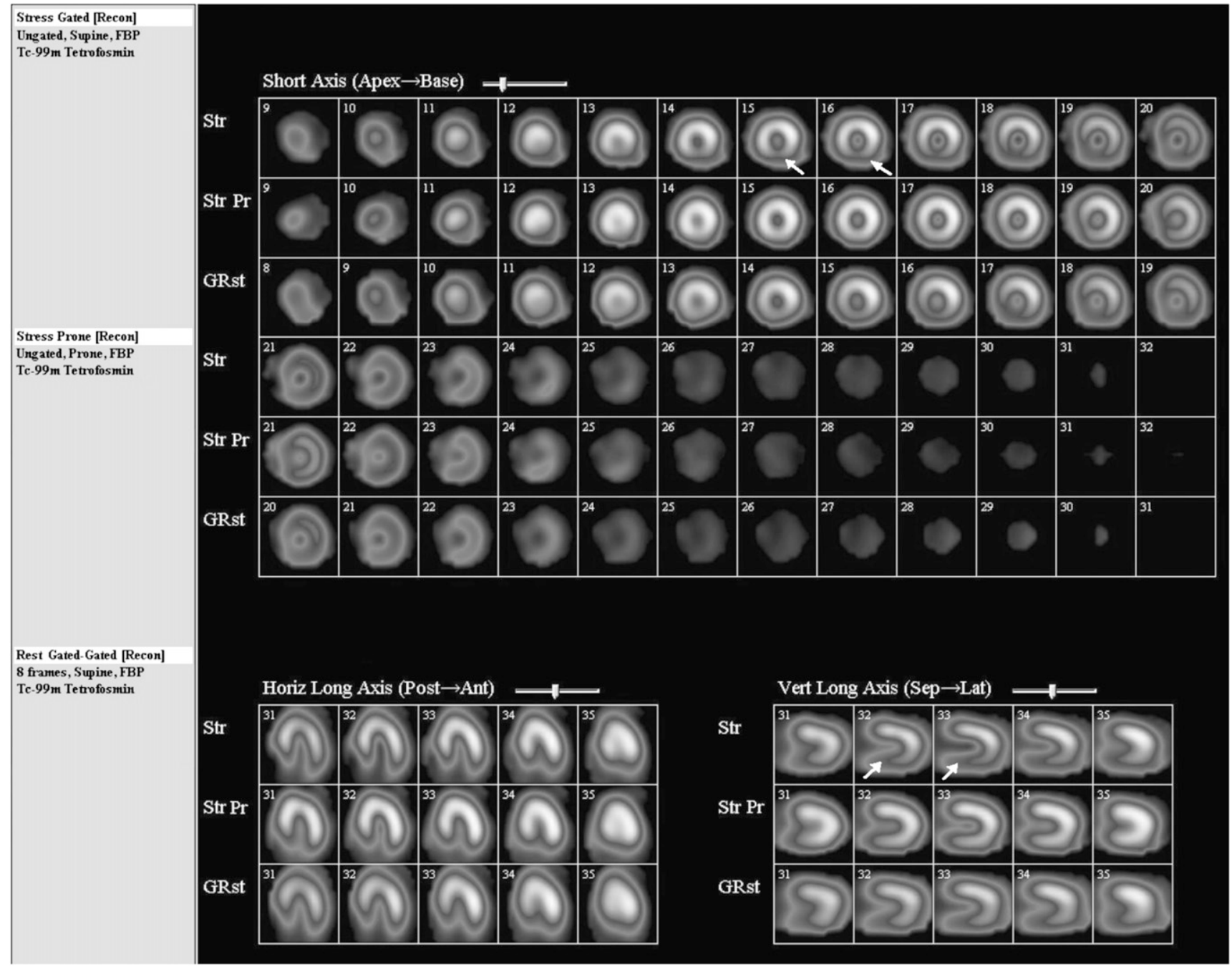

FIGURE 6. Myocardial perfusion imaging using supine and prone stress technique clearly demonstrates that inferior wall artifact (arrows) caused by diaphragmatic attenuation in obese male patient is corrected on prone images (middle row).

the problem can sometimes be resolved by performing SPECT of the region of interest. Different techniques for attenuation correction have been proposed for better image quality and enable better quantification (31).

Similarly, in a study on sentinel lymph node biopsy in 842 breast cancer patients, unsuccessful mapping was significantly higher in patients with a body mass index greater than 30 than in those less than 30 (14/113 [12.4\%] vs. $8 / 425$ [1.9\%], respectively; $P<0.001$ ), among other factors (32).

The addition of SPECT/CT to the acquisition protocol used for lymphoscintigraphy in overweight and obese patients improves nodal identification and avoids falsepositive interpretations of sites of nonnodal uptake (33).

Another example of the effect of fat crease attenuation on image quality during whole-body bone or gallium scans is seen in Figure 10. The folded skin creates thicker soft tissue overlying the imaged area of interest, causing linear abnormally increased uptake at the edge of the fat crease. If at the level of a vertebral body, this artifact could be mistaken for a compression fracture (34). This can also affect bone densitometry studies, causing falsely higher values at the level of the crease. The amount of soft tissue in obese patients has been observed to cause diffusely increased skull activity on bone scans due to disparate attenuation of overlying soft tissues (35).

\section{Steatopygia}

A high degree of fat accumulation in the buttocks can cause marked attenuation and a decrease in counts in the lumbar spine and pelvic region, obscuring or mimicking disease (Fig. 11). SPECT acquisitions can help in such situations to confirm or rule out any disease.

\section{Quantitation Difficulties}

Standardized uptake value takes into account the differences between normalizing for body weight, for lean body mass, and for surface area. Obese or overweight patients usually have an overestimated standardized uptake value when calculated using patient weight. Although not popular, using lean body mass or body surface area usually 


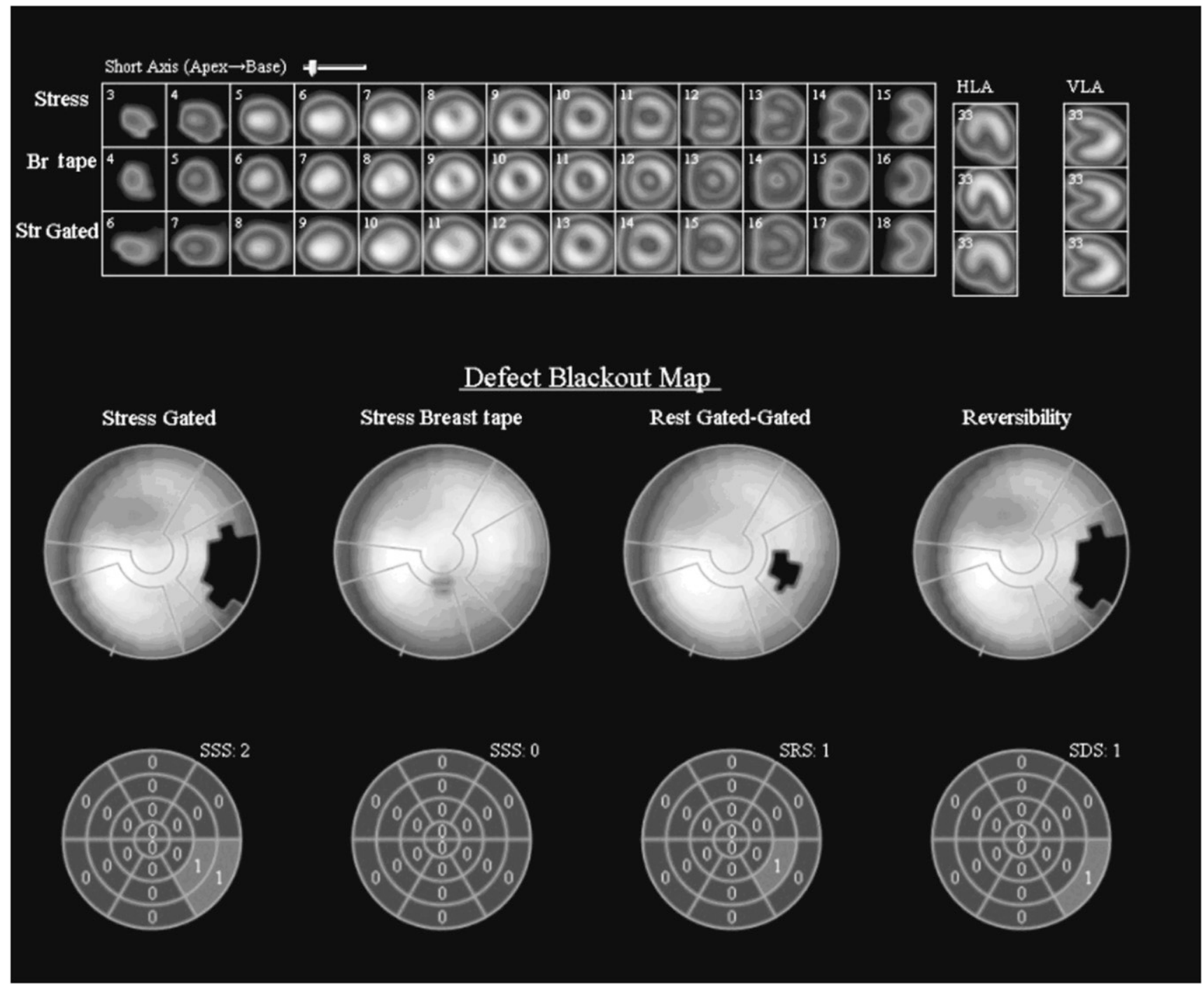

FIGURE 7. Myocardial perfusion imaging using stress technique and breast taping (middle-row images and second-from-left bull's-eye) clearly demonstrates that anterolateral wall artifact caused by large-breast attenuation in obese female patient is corrected with breast-lifting technique.

produces less variability by more consistently describing a body volume into which tracer distributes (36-38). Standardized uptake value in obese patients should be used with caution.

The amount of attenuation tissue is considered an important factor in other quantification measurements, such as the calculation of left ventricular ejection fraction in multiple gated acquisitions of the heart or even the quantification of radiotracer uptake in the sacroiliac joints for evaluating inflammation on bone scintigraphy.

\section{ROLE OF NUCLEAR PHYSICIANS AND TECHNOLOGISTS}

Physicians must be familiar with the patient's weight and other features when dealing with obese patients and should plan the study accordingly with proper communication with the technologist.
It is important that technologists working in any department of nuclear medicine follow special guidelines and protocols that are optimized for obese patients as proposed

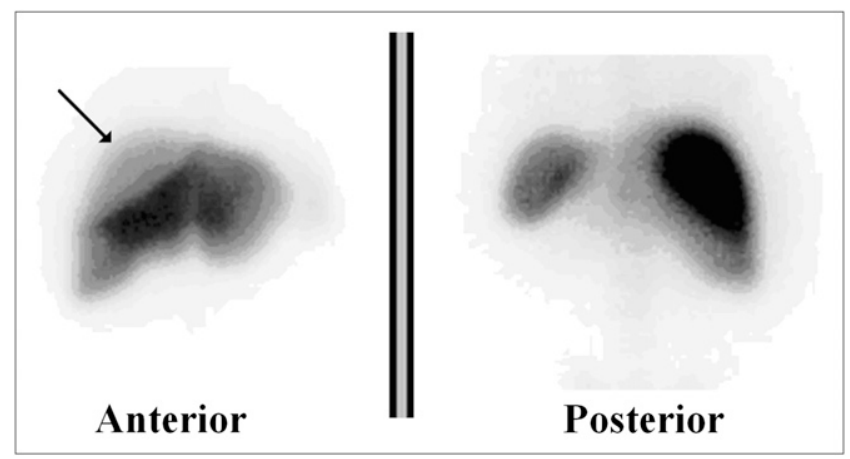

FIGURE 8. Whole-body sulfur colloid scintigraphy image shows right-breast attenuation over dome of right lobe of liver in overweight female patient. 

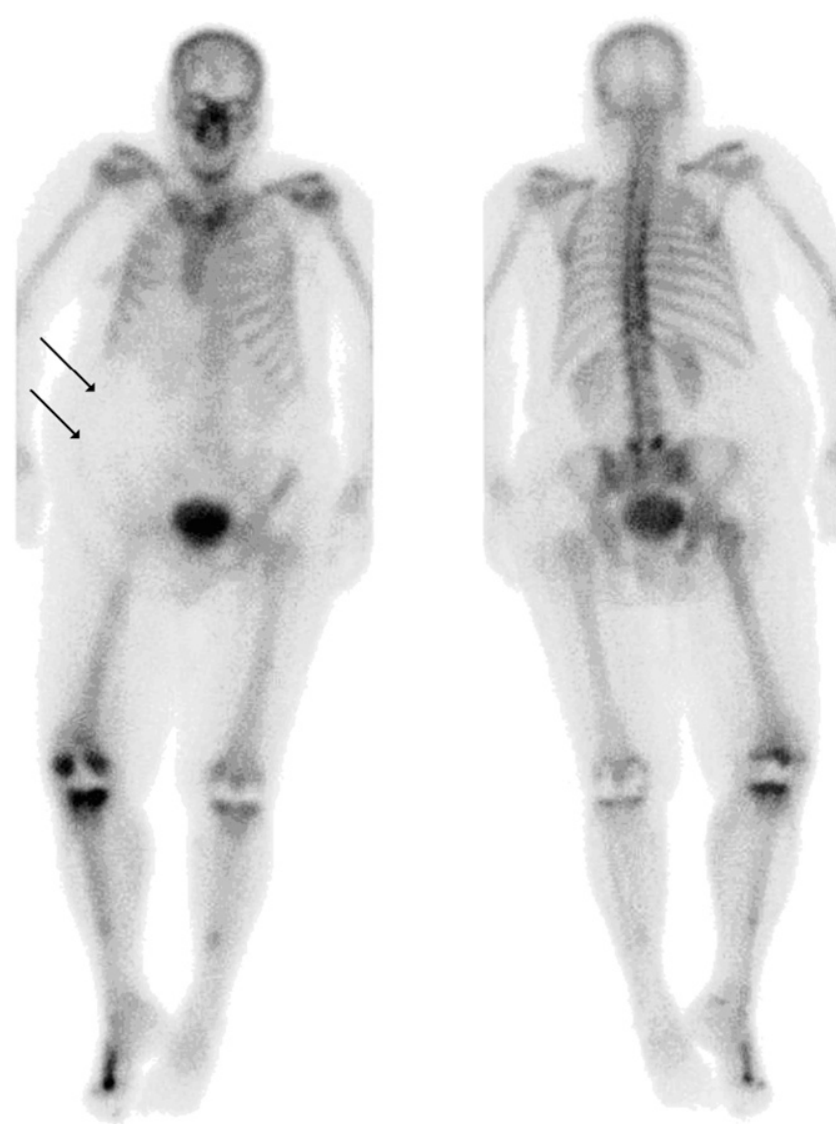

FIGURE 9. Photon attenuation caused by massive abdominal fat, which renders interpretation of lumbar spine and pelvis difficult on anterior view of this male subject.

in Table 1. Knowing the camera weight limit and bore width is important to avoid overloading the mobile table or jamming the patient into the CT or PET opening. Asking patients about their weight before they make the appointment will save the staff a lot of time and prevent unnecessary cancellations. In addition, choosing the right dose and camera setting with the proper energy windowing is essen-

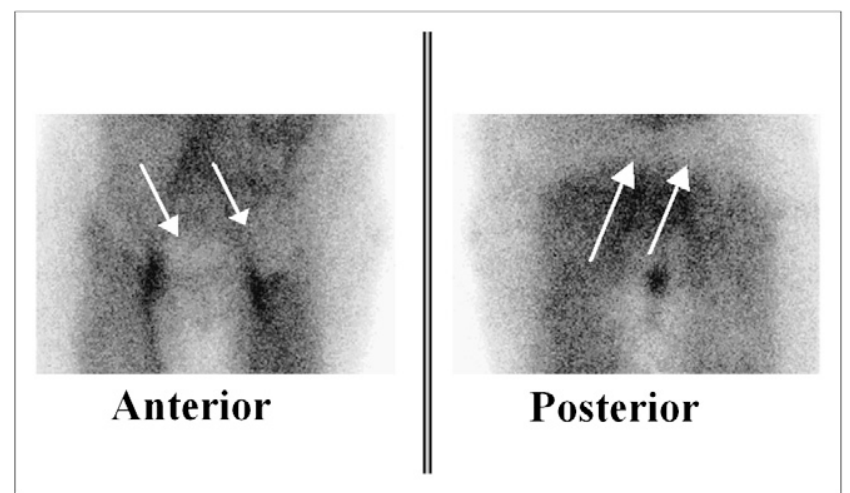

FIGURE 10. Fat tissue over lower abdomen and buttocks on gallium scan causes soft-tissue attenuation of detected photons on anterior and posterior views. tial to get an acceptable image quality. If patient manipulation is required before and after placement under the $\gamma$-camera, an extra hand is probably advisable to avoid technologist injury or prolonged radiation exposure (18). Proper communication with the referring physician and nuclear medicine staff is mandatory to ensure a safe and smooth transfer of the patient.

\section{CONCLUSION}

No less than other medical services, nuclear medicine services are affected by obesity in important and variable ways. If nuclear medicine personnel make proper arrangements, problems arising during patient transportation, preparation, and imaging can be limited. Special protocols should be established to deal with overweight and obese patients, depending on the prevalence of this problem in the serviced area. Such preparations can help correct for the artifacts arising from obesity and in the interpretation of images and can improve imaging outcomes in these patients.

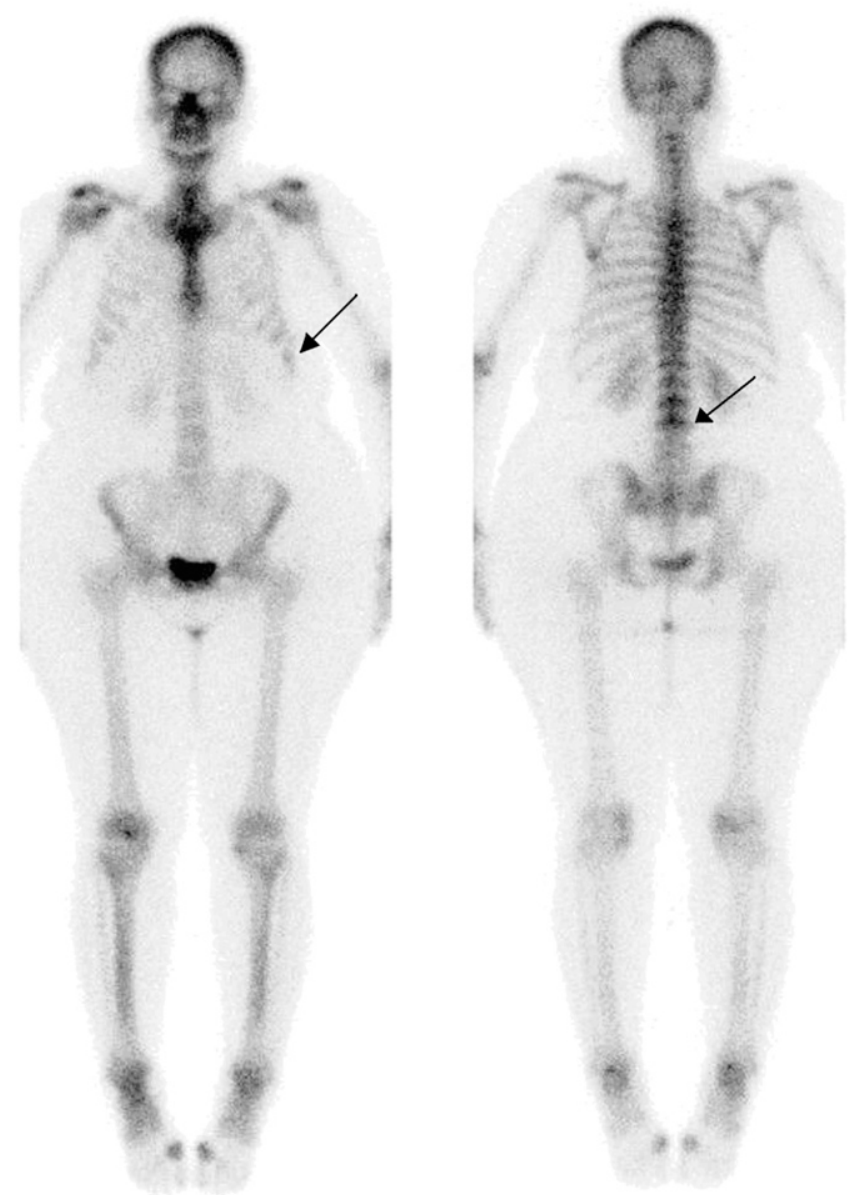

FIGURE 11. Whole-body bone scan of obese patient illustrates effect of body build on images. Attenuation is seen in region of lower lumbar spine and pelvis, in addition to edge artifact caused by fat crease in mid posterior lumbar spine and, to lesser extent, in anterior ribs. 
TABLE 1

Main Effects of Obesity on Nuclear Medicine Imaging and Possible Remedies

\begin{tabular}{|c|c|c|}
\hline Obesity-related difficulty & Impact on imaging & Possible remedy \\
\hline Body configuration & Attenuation & $\begin{array}{l}\text { Proper preparation such as adequate hydration } \\
\text { (higher amount) } \\
\text { Increase of injected activity } \\
\text { Delayed acquisition in some studies } \\
\text { Increased time of acquisition }\end{array}$ \\
\hline Access to veins & $\begin{array}{l}\text { Possible infiltration } \\
\text { Patient discomfort }\end{array}$ & $\begin{array}{l}\text { Use of more experienced nuclear medicine technologist } \\
\text { Use of intravenous team } \\
\text { Help from an anesthesiologist } \\
\text { Use of ultrasound-guided peripheral intravenous } \\
\text { access injection method }\end{array}$ \\
\hline Patient mobility & Possible fall injuries & $\begin{array}{l}\text { Use of greater caution } \\
\text { Use of accessory gadgets } \\
\text { Imaging of patient on stretcher (mobile camera } \\
\text { may be needed) } \\
\text { Adequate communication with patient }\end{array}$ \\
\hline Positioning for acquisition & Difficulty in achieving proper positions & $\begin{array}{l}\text { Attention to proper and secured positioning } \\
\text { Use of pillow, splints, or other means to ensure } \\
\text { patient's comfort and thus minimize motion }\end{array}$ \\
\hline Body contouring & $\begin{array}{l}\text { Variable distances from camera at different } \\
\text { parts of body }\end{array}$ & $\begin{array}{l}\text { Manual adjustment of camera head to obtain } \\
\text { adequate images }\end{array}$ \\
\hline Patient girth & $\begin{array}{l}\text { Compton scatter } \\
\text { Insufficient count statistics } \\
\text { Beam-hardening artifact on CT. } \\
\text { Reduced sensitivity to peripheral lesions }\end{array}$ & $\begin{array}{l}\text { Use of narrower or asymmetric energy window } \\
\text { Increase of acquisition time } \\
\text { Use of caution during reading and quantification } \\
\text { Comparison with non-attenuation-corrected images } \\
\text { Acquisition of additional spot image studies }\end{array}$ \\
\hline $\begin{array}{l}\text { Diaphragmatic attenuation } \\
\text { (cardiac) }\end{array}$ & $\begin{array}{l}\text { Masking of underlying organ activity } \\
\text { (inferior wall artifact) }\end{array}$ & $\begin{array}{l}\text { Use of prone acquisition in myocardial perfusion } \\
\text { Use of attenuation correction }\end{array}$ \\
\hline Breast attenuation (cardiac) & $\begin{array}{l}\text { Masking of underlying organ activity } \\
\text { (anteroseptal-lateral wall defect) }\end{array}$ & $\begin{array}{l}\text { Breast lifting and binding } \\
\text { Use of attenuation correction }\end{array}$ \\
\hline Fat crease and steatopygia & $\begin{array}{l}\text { Edge effect/attenuation } \\
\text { Masking of bone details and creation } \\
\text { of false findings }\end{array}$ & $\begin{array}{l}\text { Manipulation of crease and reimaging, or } \\
\text { addition of SPECT } \\
\text { Addition of extra views or SPECT }\end{array}$ \\
\hline
\end{tabular}

\section{REFERENCES}

1. Gu D, He J, Duan X, et al. Body weight and mortality among men and women in China. JAMA. 2006;295:776-783.

2. Al-Isa AN. Body mass index, overweight and obesity among Kuwaiti intermediate school adolescents aged 10-14 years. Eur J Clin Nutr. 2004;58:1273-1277.

3. Obesity: Preventing and Managing the Global Epidemic-Report of a WHO Consultation on Obesity. Geneva, Switzerland: World Health Organization; 1998.

4. Barth N, Ziegler A, Himmelmann GW, et al. Significant weight gains in a clinical sample of obese children and adolescents between 1985 and 1995. Int J Obes Relat Metab Disord. 1997;21:122-126.

5. Troiano RP, Flegal KM. Overweight children and adolescents: description, epidemiology, and demographics. Pediatrics. 1998;101:497-504.

6. Kopelman PG. Obesity as a medical problem. Nature. 2000;404:635-643.

7. Cernerud L. Height and body mass index of seven-year-old Stockholm schoolchildren from 1940 to 1990. Acta Paediatr. 1993;82:304-305.

8. Popkin BM, Doak CM. The obesity epidemic is a worldwide phenomenon. Nutr Rev. 1998;56:106-114.

9. Freedman DS, Srinivasan SR, Valdez RA, et al. Secular increases in relative weight and adiposity among children over two decades: the Bogalusa Heart Study. Pediatrics. 1997;99:420-426.

10. Obesity: Preventing and Managing the Global Epidemic-Report of a WHO Consultation. Geneva, Switzerland: World Health Organization, 2000. WHO Technical Report Series, no. 894.

11. Sherina MS, Rozali A. Childhood obesity: contributing factors, consequences and intervention. Mal J Nutr. 2004;10:13-22.

12. Wang G, Dietz WH. Economic burden of obesity in youths aged 6 to 17 years: 1979-1999. Pediatrics. 2002;109:E81.

13. Uppot RN, Sahani DV, Hahn PF, Kalra MK, Saini SS, Mueller PR. Effect of obesity on image quality: fifteen-year longitudinal study for evaluation of dictated radiology reports. Radiology. 2006;240:435-439.
14. Hansen CL, Goldstein RA, Berman DS, et al. Myocardial perfusion and function single photon emission computed tomography. J Nucl Cardiol. 2006;13:e97-e120.

15. Everaert H, Vanhove C, Lahoutte T, et al. Optimal dose of ${ }^{18} \mathrm{~F}-\mathrm{FDG}$ required for whole-body PET using an LSO PET camera. Eur J Nucl Med Mol Imaging. 2003;30:1615-1619.

16. Karesh SM. Principles of radiopharmacy. In: Henkin RE, Bova D, Dillehay GL,et al., eds. Nuclear Medicine. 2nd ed. Philadelphia, PA: Mosby/Elsevier; 2006:342-343.

17. Keyes LE, Frazee BW, Snoey ER, Simon BC, Christy D. Ultrasound-guided brachial and basilic vein cannulation in emergency department patients with difficult intravenous access. Ann Emerg Med. 1999;34:711-714.

18. Botkin CD, Osman MM. Prevalence, challenges, and solutions for ${ }^{18} \mathrm{~F}-\mathrm{FDG}$ PET studies of obese patients: a technologist's perspective. J Nucl Med Technol. 2007;35:80-83.

19. Costantino TG, Parikh AK, Satz WA, Fojtik JP. Ultrasonography-guided peripheral intravenous access versus traditional approaches in patients with difficult intravenous access. Ann Emerg Med. 2005;46:456-461.

20. Uppot RN, Sahani DV, Hahn PF, Gervais D, Mueller PR. Impact of obesity on medical imaging and image-guided intervention. AJR. 2007;188:433-440.

21. Surli S, Karp J, Werner M, et al. Imaging performance of an LYSO-based TOF PET scanner [abstract]. J Nucl Med. 2006;47(suppl):54P.

22. Li J, Udayasankar UK, Toth TL, Seamans J, Small WC, Kalra MK. Automatic patient centering for MDCT: effect on radiation dose. AJR. 2007;188: 547-552.

23. Nishina H, Slomka PJ, Abidov A, et al. Combined supine and prone quantitative myocardial perfusion SPECT: method development and clinical validation in patients with no known coronary artery disease. J Nucl Med. 2006;47:51-58.

24. Barnes WE. In vivo quantification of activity by planar imaging. In: Henkin RE, Bova D, Dillehay GL, et al., eds. Nuclear Medicine. 2nd ed. Philadelphia, PA: Mosby/Elsevier; 2006:179-180. 
25. Watson CC, Casey ME, Bendriem B, et al. Optimizing injected dose in clinical PET by accurately modeling the counting rate response functions specific to individual patient scans. J Nucl Med. 2005;46:1825-1834.

26. Halpern BS, Dahlbom M, Auerbach MA, et al. Optimizing imaging protocols for overweight and obese patients: a lutetium orthosilicate PET/CT study. J Nucl Med. 2005;46:603-607.

27. Kojima A, Matsumoto M, Takahashi M, Uehara S. Effect of energy resolution on scatter fraction in scintigraphic imaging: Monte Carlo study. Med Phys. 1993;20: 1107-1113.

28. Berman DS, Kang X, Nishina H, et al. Diagnostic accuracy of gated Tc-99m sestamibi stress myocardial perfusion SPECT with combined supine and prone acquisitions to detect coronary artery disease in obese and nonobese patients. J Nucl Cardiol. 2006;13:191-201.

29. Downer J. Hybrid SPECT.CT: making a difference. Medical Solutions: Changing the Way Healthcare Is Delivered. June 2006: 79-83. Availableat: http://www.medical. siemens.com/siemens/en_US/rg_marcom_FBAs/files/brochures/magazin_ 2006/solution_internet_june_06_eng.pdf. Accessed December 20, 2010.

30. Weiner GM, Jenicke L, Mueller V, Bohuslavizki KH. . Artifacts and non-osseous uptake in bone scintigraphy: imaging reports of 20 cases. Radiol Oncol. 2001;35: 185-191.

31. Case JA, Licho R, King MA, Weaver JP. Bone SPECT of the spine: a comparison of attenuation correction techniques. J Nucl Med. 1999;40:604-613.
32. Goyal A, Newcombe RG, Chhabra A, Mansel RE; ALMANAC Trialists Group. Factors affecting failed localisation and false-negative rates of sentinel node biopsy in breast cancer: results of the ALMANAC validation phase. Breast Cancer Res Treat. 2006;99:203-208.

33. Lerman H, Lievshitz G, Zak O, Metser U, Schneebaum S, Even-Sapir E. Improved sentinel node identification by SPECT/CT in overweight patients with breast cancer. J Nucl Med. 2007;48:201-206.

34. Elgazzar AH. Basic sciences of bone and joint disease. In: Elgazzar AH. Orthopedic Nuclear Medicine. New York, NY: Springer; 2004:26.

35. Lorberboym M, Macadziob S, Nikolov G, Kim CK. The hot skull sign on bone scans of obese patients resulting from disparate soft tissue attenuation. Clin $\mathrm{Nucl}$ Med. 2005;30:680-681.

36. Basu S, Zaidi H, Houseni M, et al. Novel quantitative techniques for assessing regional and global function and structure based on modern imaging modalities: implications for normal variation, aging and diseased states. Semin Nucl Med. 2007;37:223-239.

37. Schomburg A, Bender H, Reichel C, et al. Standardized uptake values of fluorine-18 fluorodeoxyglucose: the value of different normalization procedures. Eur J Nucl Med. 1996;23:571-574.

38. Thie JA. Understanding the standardized uptake value, its methods, and implications for usage. J Nucl Med. 2004;45:1431-1434. 